\title{
Effect of Stirring Velocity in Micro Fused-Casting for Metal on Microstructure and Mechanical Properties of A356 Aluminum Alloy Slurry
}

\author{
LUO Xiaoqiang ${ }^{1,2}$, LI Zhengyang2*, SHI Xiaojiao', YAN Qingzhi ${ }^{*}$ \\ (1. School of Materials Science and Engineering, University of Science and Technology Beijing, Beijing 100083, China; 2. Institute of \\ Mechanics, Chinese Academy of Sciences, Beijing 100190, China)
}

\begin{abstract}
A novel micro fused-casting for metal (MFCM) process for producing A356 aluminum alloy slurry was proposed. MFCM means that the refined metal slurry is pressed out from the outlet of bottom of crucible to the horizontal movable plate. With the aid of 3D manufacturing software, the melt is solidified and formed layer by layer. The stirring could keep the ingredients and the heat diffusion of metal slurry uniform in the crucible due to the shear force breaking down the dendrite arms. The solidus and liquidus temperatures of A356 alloy were 559.2 and $626.3{ }^{\circ} \mathrm{C}$, respectively, which were measured by differential scanning calorimetry (DSC). Effect of different stirring velocities of MFCM on the microstructure and mechanical properties of A356 slurry was investigated with the pouring temperature controlled at $620{ }^{\circ} \mathrm{C}$. The microstructure and mechanical performance were the best when the stirring velocity was $1200 \mathrm{r} / \mathrm{min}$ in MFCM. The microstructures of the A356 aluminum alloy slurry were mainly composed of fine spherical or rose grains. The average roundness and average grain size reached 2.2 and $41 \mu \mathrm{m}$ and the tensile strength of A356 alloy slurry reached $207.8 \mathrm{MPa}$, while the average vickers hardness was $81.1 \mathrm{HV}$.
\end{abstract}

Key words: micro fused-casting; stirring velocity; microstructure; mechanical property

\section{Introduction}

Micro fused-casting for metal (MFCM) is an original direct manufacturing processing technology translating virtual solid model data into products in a layer by layer process. In the field of additive manufacturing (AM), researchers usually fabricate the metal final parts or near-net parts by fusing wire or powder of raw materials and combining the liquid metal layer by layer ${ }^{[1-4]}$.

Many methods of additive manufacturing have been developed, such as the method of droplets without mould offered by Orme in $1990 \mathrm{~s}^{[5]}$, and the fused deposition modeling put forward by Crump which can separately deposit the part and support materials ${ }^{[6-8]}$. Laser engineered net shaping uses fast moving high

CWuhan University of Technology and SpringerVerlag Berlin Heidelberg 2016 (Received: Oct. 20, 2015; Accepted: July 3, 2016)

LUO Xiaoqiang(罗晓强) : Ph D student; E-mail: 1xq.5566 (a) $163 . c 0 m$

*Corresponding author: LI Zhengyang(李正阳): Assoc. Prof.; Ph D; E-mail: 903737505@qq.com; YAN Qingzhi(燕青芝): Prof.; Ph D; E-mail: qzyan@ustb.edu.cn

Funded by the National Natural Science Foundation of China(No. 51341009) energy laser beam to form a partially molten pool with metal powders and wires molten in the pool synchronically ${ }^{[9,10]}$. In the research of manufacturing technology, the semi-solid metal slurry is an important factor for the fabrication of parts with better mechanical properties compared to module made by conventional casting ${ }^{[11-13]}$. Semi-solid metal processing has a number of advantages, such as low porosity, consistent and reliable mechanical properties, the ability to make complex component shapes and long service life ${ }^{[14-17]}$.

MFCM is a promising rapid prototyping fabrication technology for metal materials. The refined liquid metal is continuously pressed out from the outlet at the bottom of the crucible to a horizontal movable plate under the outlet. With the aid of 3D manufacturing software, the liquid metal can solidify and form components layer by layer without mold. By integrating design, processing and molding, this technology reduced the sophisticated processing equipment and energy consumption, and thus has broad applications in aerospace, automobile industry and other fields ${ }^{[18]}$.

In this work, the slurry of A356 alloy was prepared by MFCM, and the effect of stirring velocity 
on mechanical properties and microstructure of A356 slurry had been studied. The results showed that when the stirring velocity was $1200 \mathrm{r} / \mathrm{min}$ the microstructure and mechanical performance were the best.

\section{Experimental}

\subsection{Principle of MFCM}

MFCM consists of a fused-casting mold, a movable plate, a pressure control system with a stirrer, and a heating system with a crucible, an argon gas protection device and a heating furnace. The fusedcasting freeform manufacturing system, which consists of a program multiple axes controller and a 3D movement platform, is used to form parts by controlling the motion of the 3D platform according to data information. The inert environment control system, which is made up of a glove-box and a gas circulating device, is used to protect the molten metal from oxidation. The models are designed by the CAD software and transformed into the readable data to the industrial computer, which can control the system to complete the fabrication of components.

During the process of fabrication, liquid metal is stirred vertically and pressured out though the nozzle to the fused-casting zone, which is an open flat space between the nozzle and the plate with the diameter of millimeters and the thickness of micrometers. Meanwhile, the plate, served as the crystallizer and the cooler, moves horizontally at a given velocity when the liquid metal solidifies on the plate. Controlled by the 3D controlling system, liquid metal solidifies in given patterns layer by layer, and then forms metal parts. In the fused-casting zone, the temperature gradient, the status of inflows and the velocity of the plate, can influence the performances and mechanical properties of solidified structures of aluminum alloys. In the process, the slurry of A356 alloy has great effect on the microstructure and mechanical performance of products

\subsection{Materials}

In this experiment, a commercial A356 aluminum silicon cast alloy was used. The chemical composition of A356 is listed in Table 1. The density was $2610 \mathrm{~kg} /$ $\mathrm{m}^{3}$.

Table 1 Composition of $\mathrm{A356/wt} \%$

\begin{tabular}{cccccccc}
\hline $\mathrm{Si}$ & $\mathrm{Fe}$ & $\mathrm{Mn}$ & $\mathrm{Zn}$ & $\mathrm{Mg}$ & $\mathrm{Ni}$ & $\mathrm{Cu}$ & $\mathrm{Al}$ \\
\hline 7.5 & 0.6 & 0.2 & 0.25 & 0.3 & 0.2 & 0.15 & Bal. \\
\hline
\end{tabular}

\subsection{Slurry preparation}

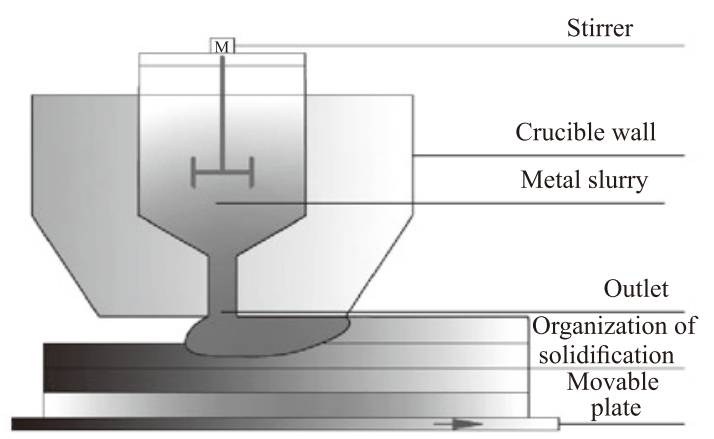

Fig.1 Micro fused-casting for metal slurry

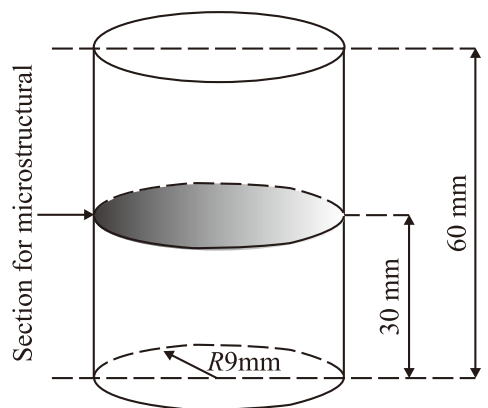

Fig.2 Sample location for semi-solid microstructure analysis

As shown in Fig.1, in order to obtain globular and fine microstructure, the A356 aluminum silicon alloys were heated to a temperature between solidus temperatures and liquidus temperatures which is the sufficient condition required for the forming. Therefore, this window of heating temperature could be controlled within liquidus temperatures and solidus temperatures to get a proper solid fraction and a proper degree of superheat. As the Scheil equation, at a given temperature during the isothermal heat treatment of semi-solid, the volume fraction of solid and liquid in the alloys should be a constant value, with the assumption that the homogenization of the liquid is complete and stable in the solid. In this experiment, we chose the pouring temperature to be $620{ }^{\circ} \mathrm{C}$, and controlled the stirring velocity from 0 to $1800 \mathrm{r} / \mathrm{min}$ with $T_{1}$ thermal treatment of the samples involved artificial aging for the A356 aluminum alloy slurry. The samples for microstructure observation were prepared by standard metallographic techniques. For microstructures observation samples were cut off from the A356 aluminum alloy slurry, roughly ground and polished and etched by an aqueous solution of $0.5 \% \mathrm{HF}$ for $15 \mathrm{~s}$, the etched samples were cleaned with an alcohol and dried, then analyzed by optical microscopy $(\mathrm{OM})$, and the representative microstructure of the slurry can be obtained. All the metallographic 
samples were examined by OM, SEM and EDS (Evo-18). Fig.2 shows the schematic drawing of the sample location for A356 aluminum silicon cast alloy microstructure analysis.

Therefore, this window of heated temperature could be controlled within liquids temperatures and solidus temperatures to get a proper solid fraction and a proper degree of superheat.

\subsection{Testing methods}

The average roundness of the grain shape was calculated by

$$
S=L_{\mathrm{p}}^{2} /\left(4 \pi A_{\mathrm{p}}\right)
$$

where $S$ is the average roundness, $L_{\mathrm{P}}$ and $A_{\mathrm{P}}$ are total circumference of grains and grain areas value of globule, respectively. The average roundness of the grain shape was calculated by image analysis software.

The average grain size was calculated by

$$
D=L_{\mathrm{f}} /\left(N_{\mathrm{f}} \times \mu\right)
$$

where $D$ is the average grain size, $L_{\mathrm{f}}$ is the length of measured line, $N_{\mathrm{f}}$ is the grain count that is covered by the measured line and $\mu$ is the magnification value.

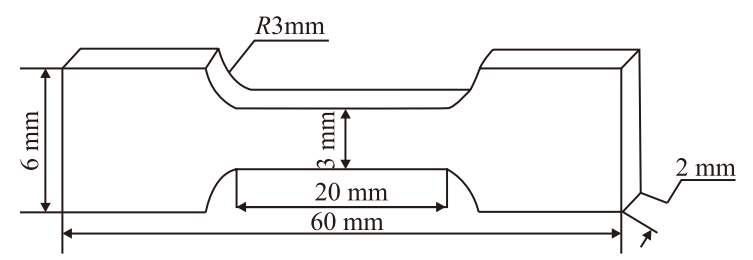

Fig.3 Schematic illustration of tensile test

A356 cast alloy has been used for fabricating tensile samples. The tensile samples for mechanical property tests were obtained from middle region, the samples were machined to specimens shown in Fig.3, and the tensile test was carried out by a CMT5105 tensile machine, the results of the tensile tests reported in this work were the average obtained from five tensile test specimens. The hardness was test by a XHB-3000 Brilled duromete. The samples were tested by using a $62.5 \mathrm{~kg}$ load and $5 \mathrm{~mm}$ diameter indentor, and the loading time was about $30 \mathrm{~s}$.

\section{Results and discussion}

\subsection{Differential scanning calorimetry}

The relationship between the solid volume fraction and the temperature of the commercial A356 aluminum alloy was investigated by DSC. The samples with diameter of $5 \mathrm{~mm}$ and mass of $20 \mathrm{mg}$ were put into carbon pans with carbon lids in argon atmosphere. The heat flow and temperature were monitored by thermocouples to obtain heating and cooling curves. By integrating these curves, the curve of solid volume fraction versus temperature was obtained and is shown in Fig.4. The solidus and liquidus temperatures of this alloy were 559.2 and $626.3{ }^{\circ} \mathrm{C}$, respectively.

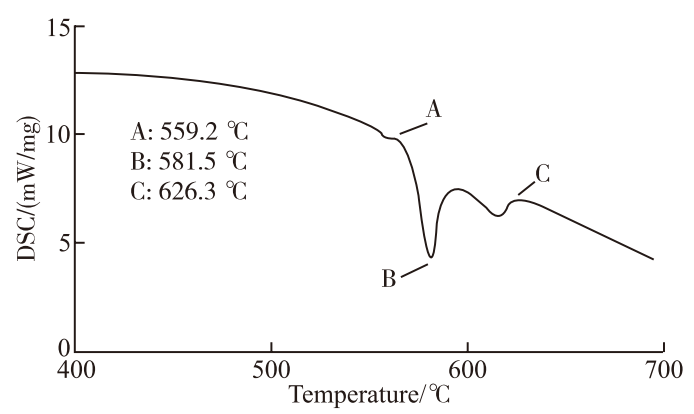

Fig.4 DSC curve of A356

\subsection{Microstructure of $\mathbf{A 3 5 6}$ alloy}

Fig. 5 shows the backscattered electron (BSE) image and EDS spectra of two regions on the A356 aluminum alloy samples, which is produced under the pouring temperature of $620{ }^{\circ} \mathrm{C}$ and stirring velocity of $1200 \mathrm{r} / \mathrm{min}$. A356 alloy exhibited typical globular crystal microstructure and was mainly composed of eutectic Si (white precipitates, point 1) and eutectic $\alpha$-Al matrix (grey precipitates, point 2). A356 aluminum alloy had complex irregular shape, and the $\alpha$-Al phase mainly exhibited large block shape.

Fig. 6 shows the optical microstructure images of A356 alloys prepared by MFCM at the pouring temperature of $620{ }^{\circ} \mathrm{C}$, and different stirring velocities, which were 0 (Fig.6(a)), 600 (Fig.6(b)), 1200 (Fig.6(c)) and 1800 r/min (Fig.6(d)), respectively. Four samples
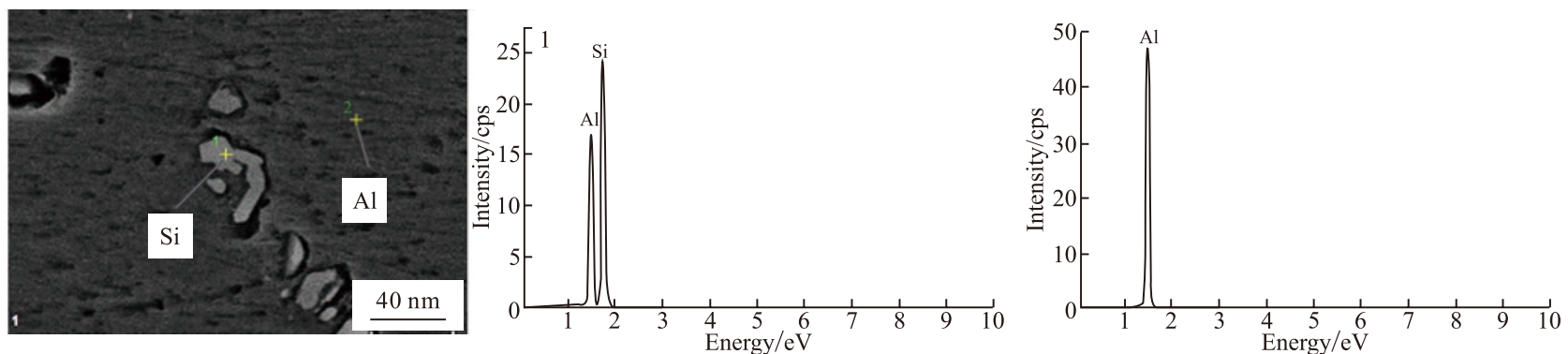

Fig.5 BSE and EDS image of A356 alloy samples (point 1 was eutectic Si, point 2 was eutectic $\alpha$-Al matrix) 

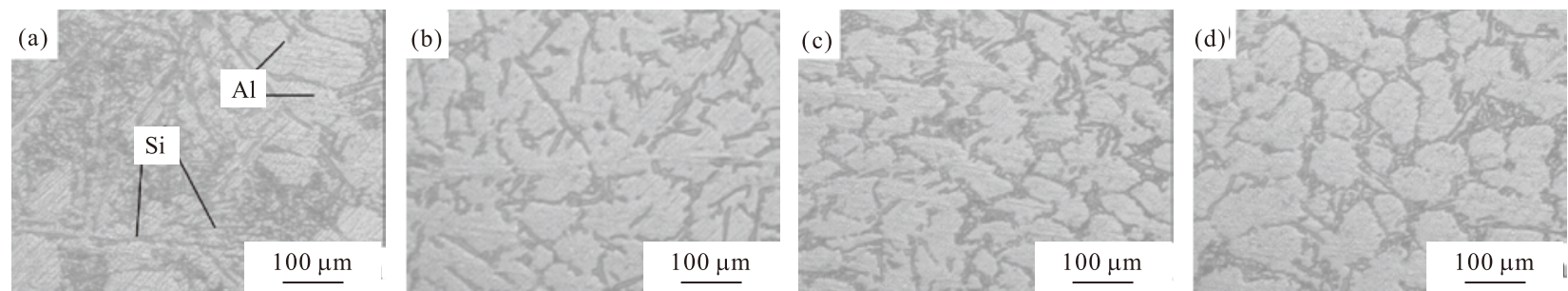

Fig.6 OM images of the A356 alloys prepared by MFCM under different stirring velocity: (a) $0 \mathrm{r} / \mathrm{min}$; (b) $600 \mathrm{r} / \mathrm{min}$; (c) $1200 \mathrm{r} / \mathrm{min}$; (d) $1800 \mathrm{r} / \mathrm{min}$

were cooled at room temperature ( $T_{1}$ state). It can be found that the stirring velocity had great influence on material morphologies. Fig.6(a) shows the typical dendritic microstructures, which were changed to short grains when the stirring velocity was increased. So, a proper stirring velocity was the key factor to achieve short and fine grains. The sample prepared under $1200 \mathrm{r} / \mathrm{min}$ stirring velocity has the most uniform microstructure and fewest dendrite.

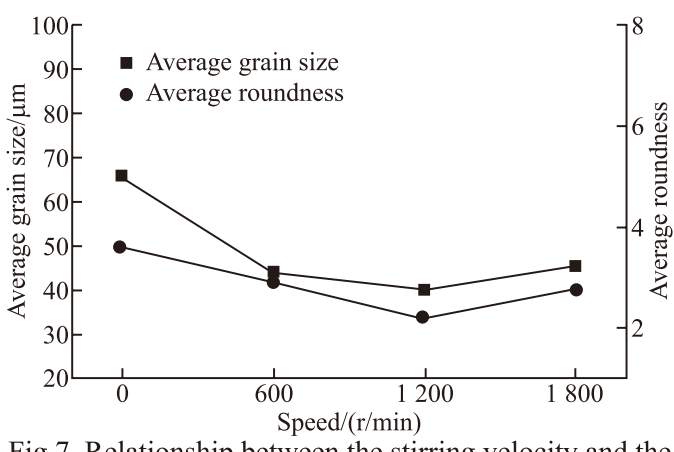

Fig.7 Relationship between the stirring velocity and the average grain size

Fig.7 shows the relationships between the stirring velocity, average roundness and average grain size. The primary grain size is best developed at speed of 1200 $\mathrm{r} / \mathrm{min}$, the stirring velocity can affect the nucleation rate and shearing strength of the slurry, and further influence the final grain size of the A356 alloy slurry. The average roundness and average grain size decreased with increasing stirring velocity from $1200 \mathrm{r} / \mathrm{min}$. As stated, the shearing force in the melt is determined by the viscosity of stirrer, so the shearing strength reduces with the decrease of the viscosity of A356 slurry. For this reason, a low stirring velocity could have caused a weak shearing strength and low nucleation rate, which caused coarse dendrite formation. On the other side, too much of the shearing strength made the A356 alloy slurry segregation, as shown in Fig.8(d). For these reasons we suggest a reasonable stirring velocity of $1200 \mathrm{r} / \mathrm{min}$. When the stirring velocity is $1200 \mathrm{r} / \mathrm{min}$, the average roundness and average grain size reach 2.2 and $41 \mu \mathrm{m}$, respectively.
Fig. 8 shows the scanning electron microscopy of four samples. Fig.8(a) is the A356 aluminum alloy with stirring velocity at $0 \mathrm{r} / \mathrm{min}$. In Fig.8(b), Fig.8(c) and Fig. $8(\mathrm{~d})$ the stirring velocity was controlled at 600, 1 200, $1800 \mathrm{r} / \mathrm{min}$ respectively, and the samples were cooled at room temperature $\left(T_{1}\right.$ state). It could be seen that when the stirring velocity was $1200 \mathrm{r}$ / min, the alloy had the most uniform microstructure and the fewest dendrite. During the heating process, fast stirring velocity could prevent segregation and help to prepare homogenous melt. During the cooling process, rapid and uniform cooling and fast stirring were beneficial to the refinement and homogeneity of grains. However, too fast stirring velocity could also make the grains to segregate, and thus reduce the mechanical performance of the material. So a proper stirring velocity was preferred.

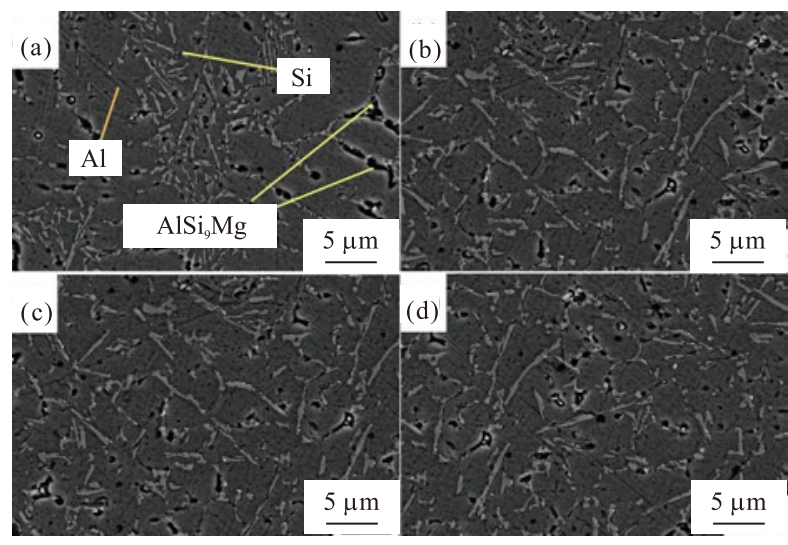

Fig. 8 SEM images of the A356 alloys prepared by MFCM under different stirring velocity: (a) $0 \mathrm{r} / \mathrm{min}$; (b) $600 \mathrm{r} / \mathrm{min}$; (c) 1200 $\mathrm{r} / \mathrm{min}$; (d) $1800 \mathrm{r} / \mathrm{min}$

\subsection{Tensile}

Tensile properties of A356 alloys with different stirring velocity are presented in Fig.9. For each condition, at least five tensile tests were performed. Curve a in the figure shows that the tensile strength of samples with stirring velocity of $0 \mathrm{r} / \mathrm{min}$ is $147.8 \mathrm{MPa}$. The segregation of microstructure could decrease the material strength. Curve b, curve $c$ and curve $d$ are the tensile curves with the stirring velocity controlled at 600,1200 and $1800 \mathrm{r} / \mathrm{min}$ respectively, and the 
samples were cooled at room temperature $\left(T_{1}\right.$ state). Curve $\mathrm{c}$ in the figure with stirring velocity of $1200 \mathrm{r}$ / min shows that the tensile strength of samples is 207.8 MPa. The largest tensile strength of the samples among different stirring velocities is that of curve c. Therefore, the ultimate tensile strength of sample $\mathrm{c}$ is improved by $40.6 \%$ than that of sample a. In fact, the A356 semisolid aluminum alloy with uniform microstructure and few dendrites could lead to the proper viscosity and excellent formability of the slurry, and thus enhance the tensile strength of samples.

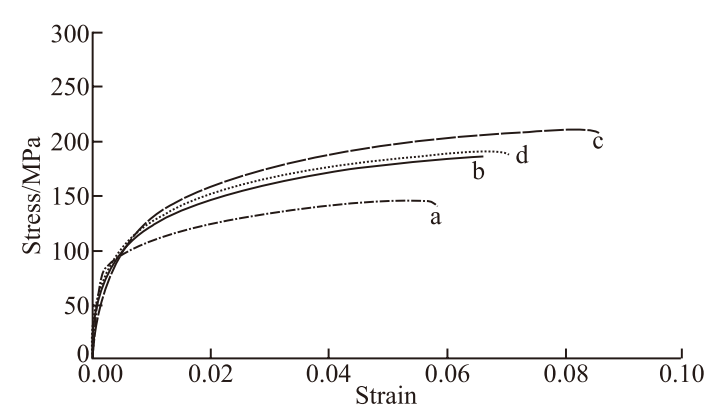

Fig.9 Stress-strain curve of the A356 semi-solid aluminum alloy: (a) $0 \mathrm{r} / \mathrm{min}$; (b) $600 \mathrm{r} / \mathrm{min}$; (c) $1200 \mathrm{r} / \mathrm{min}$; (d) $1800 \mathrm{r} / \mathrm{min}$

\subsection{Hardness}

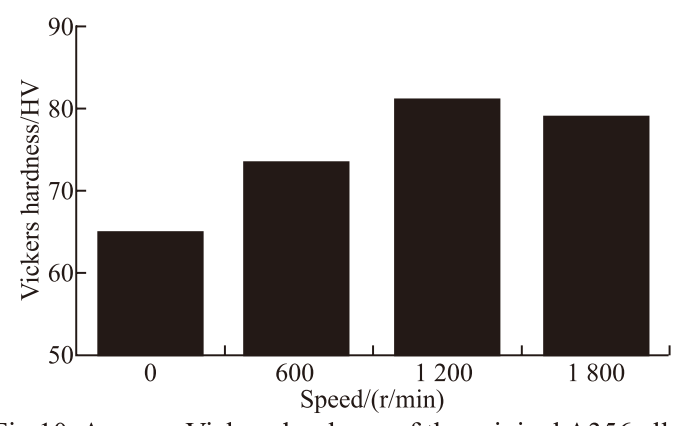

Fig.10 Average Vickers hardness of the original A356 alloy with different stirring velocities

Fig.10 is the comparison figure of four kinds of samples prepared for MFCM with different stirring velocities. For each condition, at least five vickers tests were performed. The vickers analysis sample of hardness is made in the same place of the samples. From the figure it can be seen that the average vickers hardness of five position in per sample is more than $65 \mathrm{HV}$. The largest average vickers hardness is 81.1 $\mathrm{HV}$, which is obtained at stirring velocity of $1200 \mathrm{r}$ / min. According to the data of the samples, the highest vickers hardness located in the center of sample. It can be concluded that refinement of particles could increase the material strength significantly, but the segregation of microstructure could decrease the material strength.

\section{Conclusions}

In this paper, a novel micro fused-casting for metal (MFCM) process for producing A356 aluminum alloy slurry was developed. The microstructure formation mechanism, the effects of the technical parameters of stirring velocities on the microstructure and properties of the A356 aluminum alloy slurry were investigated. The following conclusions are drawn:

a) By using the differential scanning calorimetry (DSC) analysis, the temperature range of the solidliquid region of A356 alloy slurry was roughly determined between 559.2 and $626.3{ }^{\circ} \mathrm{C}$ and the temperature of the preparation of A356 slurry was controlled near the liquidus temperatures at $620{ }^{\circ} \mathrm{C}$. In this point, the refinement and homogeneity of semisolid A356 alloy slurry grains could achieve.

b) The effect of the different stirring velocities on the microstructure evolution and mechanical property of A356 alloy slurry by MFCM was studied in this paper. When the stirring velocity in MFCM for A356 aluminum alloy slurry was controlled at 1200 $\mathrm{r} / \mathrm{min}$, the average roundness and average grain size reached 2.2 and $41 \mu \mathrm{m}$.

c) The shear force produced by the proper stirring could contribute to grain refinement and even heat distribution in the process. When the stirring velocity of MFCM for A356 aluminum alloy slurry was controlled at $1200 \mathrm{r} / \mathrm{min}$, the best microstructure and mechanical performance were obtained, the tensile strength of samples reached 207.8 MPa and Vickers hardness was $81.1 \mathrm{HV}$.

\section{Acknowledgement}

The authors thank for the supports of National Natural Science Foundation of China (No. 51341009) and professor Guangnan Chen.

\section{References}

[1] Sercombe T B, Schaffer G B. Rapid Manufacturing of Aluminum Components[J]. Sci., 2003, 301(5 637): $1225-1227$

[2] Seno T, Ohtake Y, Kikuchi Y, et al. 3D Scanning Based Mold Correction for Planar and Cylindrical Parts in Aluminum Die Casting[J]. Journal of Computational Design and Engineering, 2015, 2(2): 96-104

[3] Crump S S. Fast, Precise, Safe Prototypes with FDM[J]. Intelligent Design and Manufacturing for Prototyping, PED, 1991, 50: 53-60

[4] L Xiaoqiang, L Zhengyang, C Guangnan, et al. Effect of Substrate Movement Speed by Synchronous Rolling-Casting Freeform Manufacturing for Metal on Microstructure and Mechanical Property 
of ZL104 Aluminum Alloy Slurry[J]. J. Wuhan Univer. Technol-Mater. Sci.Ed., 2015, 30(5): 1 056-1 060

[5] Orme M. A Novel Technique of Rapid Solidification Net-Form Materials Synthesis[J]. Journal of Materials Engineering and Performance, 1993, 2(3): 399-405

[6] Crump S S. Rapid Prototyping Using FDM[J]. Modern Casting, 1992, 82(4): 36-38

[7] Thompson S M, Bian L, Shamsaei N, et al. An Overview of Direct Laser Deposition for Additive Manufacturing; Part I: Transport Phenomena, Modeling and Diagnostics[J]. Additive Manufacturing, 2015, 8: 36-62.

[8] Liska R, Schuster M, Inführ R, et al. Photopolymers for Rapid Prototyping[J]. Journal of Coatings Technology and Research, 2007, 4(4): 505-510

[9] Kunce I, Polanski M, Bystrzycki J. Microstructure and Hydrogen Storage Properties of a TiZrNbMoV High Entropy Alloy Synthesized Using Laser Engineered Net Shaping (LENS)[J]. International Journal of Hydrogen Energy, 2014, 39(18): 9 904-9 910

[10] Durejko T, Ziętala M, łazińska M, et al. Structure and Properties of the Fe 3 Al-Type Intermetallic Alloy Fabricated by Laser Engineered Net Shaping (LENS)[J]. Materials Science and Engineering: A, 2016, 650: 374-381

[11] Eskin D G, Katgerman L. Mechanical Properties in the Semi-Solid State and Hot Tearing of Aluminium Alloys[J]. Progress in Materials Science, 2004, 49(5): 629-711
[12] Chen Z, Mao W. Rheo-diecasting Performance of the Semi-Solid Slurry Prepared by Serpentine Channel Pouring and After Soaked[J]. Materials Science and Technology, 2012, 2: 14

[13] Ceschini L, Morri A, Sambogna G. The Effect of Hot Isostatic Pressing on the Fatigue Behaviour of Sand-Cast A356-T6 and A204-T6 Aluminum Alloys[J]. Journal of Materials Processing Technology, 2008, 204(1-3): 231-238

[14] Huang X S, He L J, Mi G B, et al. Characteristics of Defect Bands and Their Formation Mechanisms in A356 Wheel Fabricated by Horizontal Squeeze Casting[J]. Materials Science and Technology, 2015, 31(4): 400-408

[15] Williams J D, Deckard C R. Advances in Modeling the Effects of Selected Parameters on the SLS Process[J]. Rapid Prototyping Journal, 1998, 4(2): 90-100

[16] Flemings M C. Behavior of Metal Alloys in the Semisolid State[J]. Metallurgical Transactions B, 1991, 22(3): 269-293

[17] Esgandari B A, Nami B, Shahmiri M, et al. Effect of Mg and Semi Solid Processing on Microstructure and Impression Creep Properties of A356 Alloy[J]. Transactions of Nonferrous Metals Society of China, 2013(9): 2 518-2 523

[18] Shamsaei N, Yadollahi A, Bian L, et al. An Overview of Direct Laser Deposition for Additive Manufacturing; Part II: Mechanical Behavior, Process Parameter Optimization and Control[J]. Additive Manufacturing, 2015, 8: 12-35 